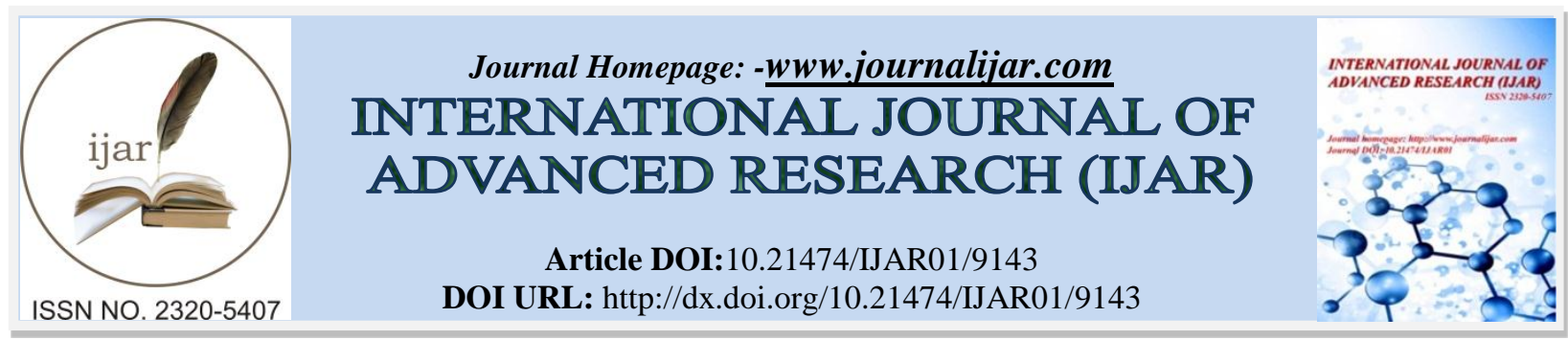

RESEARCH ARTICLE

\title{
LIFE MANAGEMENT: A PLAY OF TIME AND ENERGY A STUDY OF EASTERN MYSTICISM IN FRITJOF CAPRA'S NOVEL “ THE TAO OF PHYSICS.
}

\section{Gopika Narayanan Vasavan ${ }^{1}$ and Dr.Sreenath Muraleedharan $\mathbf{k}^{2}$.}

1. Student, BA.English,Amrita school of arts and sciences, kochi,Amrita vishwa vidyapeetam university, Ernakulam, Kerala, India.

2. Assistant Professor,Department of English and Languages, Amrita school of arts and sciences, kochi MA ,B. Ed ,M.Phil., PhD.

\section{Manuscript Info} .........................

\section{Manuscript History}

Received: 24 March 2019

Final Accepted: 26 April 2019

Published: May 2019

Key words:-

Mystics, Seeker, Reality, Existence,

Time and Space, Mind.

\section{Abstract}

Throughout the ages humans have been seeking answers to life's greatest mysteries. Why are we never satisfied with what we have? What is the real meaning of our lives? Is there an alternative reality that lies beyond the material world? Mystics are those who have dedicated their whole lives to find answers to these eternal questions. By following separate paths they have found answers to what they seek. They have discovered truth beyond all these ideologies of realities and has found an existence beyond time and space, a vision of life which is beyond the capacity of the mind to comprehend or explain we know the world only through the way it is projected in our minds .so it is important to understand the nature of the mind The sixteen dimensions of mind are explained in four parts below for easiness in understanding .The paper deals with the mystical view of reality by taking references from Frijof capra's book 'The Tao of physics'.

Copy Right, IJAR, 2019,. All rights reserved.

\section{Introduction:-}

The spirit of the east is beyond the surface of the intellect or any sensory perceptions. In the words of the Upanishads"What is soundless, touchless, formless, imperishable, tasteless, constant odourless, without a beginning and an end, higher than the great, stable - By discerning that one is liberated from the clutches of death itself."

These deductions cannot be a product of the intellect and for this reason it has to preserved and nurtured. This dimension has come from the inner experience where things are seen exactly as they are i.e. a mind that is devoid of the concept of differentiation.

The ultimate reality which is often talked about by eastern mystics can neither be subjected to reasoning nor demonstrated. It can never be put into words as it lies beyond the realms of perception and logic from which all concepts are derived.

The Upanishads says

"There the eve goes not, speech goes not nor the mind. We know not, we understand not.How would one teach it"

Corresponding Author:-Gopika Narayanan Vasavan.

Address:-Student, BA.English,Amrita school of arts and sciences, kochi,Amrita vishwa vidyapeetam university, Ernakulam, Kerala, India. 
Lao Tzu calls this reality the Tao. In his book 'Tao Te Ching' he says that the Tao which can be expressed is not the eternal one. Tao's philosophy embraces the natural way of life. The symphony of nature is more complex and intense than anything a human being can achieve.

\section{The Human Mind}

According to eastern philosophy the mind consists of four attributes. The fist one is the intellect. This attribute has to be sharp as it is a cutting tool. It is the attribute of the mind that differentiates or cuts information. It derives information from an individual's memories to make its own logic to discriminate everything it perceives. Such a tool for differentiation cannot help one achieve enlightenment or a state of oneness. It is purely a survival tool that helps human beings understand the world around him. It makes you look smart because of the information it stores

The second attribute is called identity. Identity is the base on which the intellect builds its logic. This is where education plays a major role. The current educational system instils the concept of limits or boundaries for one's identity in a child. This can lead to chaos and confusion in the mind during adulthood. He perceives another individual with a different personality as hostile. Most of the problems faces by contemporary world are not clashes between good and evil as widely believed but simply clashes between Identities or ideals be it religion, country or any other aspects of human life. Limitation of identity causes prejudiced thoughts inside an individual. A prejudiced mind can never see or reveal the reality of life. Everyday we assume different identities. Continuous identification of oneself with different identities makes us believe that we are limited by that identity and we start to define our existence through these identities. The concept of identity is defined by the mind by drawing on its vast reserves of memories of the past and present and the expectations of the future. Only by shedding these thoughts can one expand one's identity beyond one's body and identity oneself with everything that is around them. Once this state of mind is achieved the concepts of equality and brotherhood vanishes as you don't see yourself separate from others anymore.

The third attribute is called 'Manas'. This is the collection of all kinds of memories. Each cell in the body is a reservoir of information that contain genetic memory that decides their framework. The very thing that binds the mind to the body is the memory. The identity you take up is based on your memory and this is what helps our intellect to function properly. The fourth attribute of the mind is called 'Chitha' or pure intelligence is the attribute that identifies itself with everything around it. This is otherwise known as the undifferentiated mind. This mind experiences no emotions or pain nor is bound by anything. It is in a constant state of resonance with its surroundings. This is the state of mind that allows a being to understand and dissolve in the state 'Ekam', a state where no thoughts or boundaries exist. This State is beyond the comprehension of the human brain or any logic. It's a whole other dimension marked by a state of nothing, a state where time and space hold no meaning. The concept of time is used to mark an event, and concept of space is used to mark the location of that event if no event were to occur both of these concepts become null and void hence cannot exist in 'Ekam'. To reach this state is the true purpose of existence. This state cannot be reached by observing the materialistic world around this a consciousness that exists inside every individual hence only by directing our concentration inward can we know of this state.

\section{Science And Spirit}

Many Physicists of today are threatened by the comparison of these theories to mythical tradition. In his book 'The Tao of Physics' Capra argues that there exists a profound harmony between modern physics and eastern mysticism. The unlikely meeting between the ideas of the east and the west contains lessons for our survival. In search of the building blocks of the universe scientists have dived matter into experiments that deals with forces beyond the perception through the 5 senses. The subatomic realm is ruled by the laws of quantum mechanics a world in which the search for the smallest particle of creation has led to baffling complexities. To grasp this concept some scientists have turned to ancient symbols and texts in eastern mythology, during this search they came across a symbol of Lord Shiva

Whose dance represents creation as an indivisible reality. In the words of Heinrich Zimmer

"His gestures wild and full of grace, precipitate the cosmic illusion ; his flying arms and legs and the swaying of his torso produce -indeed ,they are -continuous creation - destruction of the universe, death exactly balancing birth, annihilation, the end of every coming forth. In contrast to this classical science has divided nature into separate fragments thus paving way to an inevitable crisis. The only way out is through an interplay of scientific analysis and mythical intuition. According to Capra global crisis can be seen as a crisis of perception. It comes from the fact that the Newtonian and the Cartesian world view is embodied in our social intuitions and forms the basis of the major 
problems of our time. The crisis of perception is the core of all problems .Our world view is fragmented and mechanistic and this view is used to solve problems that exist around us. This seems to be the root cause of all problems. It's high time we start to approach the world in a holistic or ecological view which shows the interdependence of all phenomenon and activities

In calling it 'The Tao of physics' he linked his own science with the world of Chinese philosopher Lao Tzu who is the founder of Taoism and a contemporary of confucious

Tao means way and Taoism is the way or path which the universe proceeds. It is the way or path towards human fulfilment. In Taoism true knowledge can only be attained through direct contact with reality Which arises in meditative state where thoughts are cleared away so that spiritual insight can arise from the depths of consciousness The same idea can be equated to Adi Sankaracharaya's verse

Aham Nirvikalpo Niraakaara-Ruupo

Vibhu-Tvaacca Sarvatra Sarve[a-I]ndriyaannaam

Na- Cha Sanggatam Naiva Muktirna Meyah

Chidananda- ruupah shivoham shivoham

Which was written 1,200 years ago in Nirvana Shatakam. The meditative state which cards talks about where no thought exists is the state of pure consciousness which Sankaracharya refers to in his verse which translates to I am without any variation and without any form

I am all pervasive as the underlying substratum of everything, and Neither do I get attached to anything, nor am I freed from anything

I am the ever pure consciousness

I am shiva; I am shiva

\section{Theory}

Consciousness as ultimate reality is not something which is conjured up as a probability or restricted to some community religion class or group of people. The dimension of life is not sacrosanct to the east or any sect of a society. Existence of this unified field is reinforced by supper string theory. The nature of reality has been under centuries of scientific investigation. This research started with the theory of quantum mechanics which then further led to the birth of quantum field theory. The state of consciousness is about experiencing the ocean of existence and stimulating into the waves of vibration and experiencing the fundamentals of mind and creation. The vibrating particle referred in quantum mechanics represents a particular energy frequency and mass. These vibrations are in power with the music of the absolute. The unified field that percolates in the universe is same as the field that percolates inside our body at the state of consciousness. The vibration of the particle at that stage is same as that of the universe. The state of mind and the consciousness within determines the aura or the electric field that surrounds us. This energy or field which surrounds us is different from person to person.

The state of particles in the unified field which percolates the universe is same as the state of particles in 'Samadhi' where the whole brain functions in synchronization. These packets of energy which are you and me are strung on a string. Everyone in this world has this field of energy. The magnitude of it varies from person to person and even though the magnitude is different we are all strung on the same string. This string which connects everything is 'Ekam'. Another evidence for the existence of such a state of mind is God's particle or Higgs Boson. The value of science is in its utility and will ultimately hit a dead end as it moves forward only with our intellect

\section{Conclusion:-}

Instead of adopting the ways of the east is Buddhism, Taoism, Hinduism, in their original forms their essential nature can be adapted and a new way of spiritual thought can be created. That is what Buddhism did . It travelled from India , China ,Japan and south east Asia. By preserving the essence the form can always transform. A profound awareness of the interdependence of all phenomenon and the embeddedness of individuals and societies in the cycle or kala chakra of nature is the start. Everything is an inter connected network and if you are violent to parts of it you become violent to yourself. The comparison between physics and mystical traditions is only a small part of a much broader change of world view and change of consciousness that is now happening in our society. A shift from a mechanistic world view to a holistic and ecological vision of reality has started. Today the world is full of people who have everything but cannot feel life. When time catches up to them, they will realise that they spent their whole 
lives without living a moment. We humans think of acquiring all things material in the universe and even if you manage to possess everything it is not enough and you waste your whole life thinking of what you can get and forget to live life.

Karma is the consequence of action and reaction and this is the crust of existence of nature. It is the cosmic law. If we can live by it we can find content and happiness in life.

\section{Bibliography:-}

1. Tao of physics-Frijof capra

2. The Tao of Nature- Chuang Tzu

3. Sounds of nature

4. String Theory and Quantum Mechanics

5. Teachings of Sankaracharya and Buddha

6. Human mind and Nature as a healer

7. Teachings of the Vedas and Upanishads

8. Science vs mysticism/ speaking tree 